\title{
The Construction of English Smart Classroom and the Innovation of Teaching Mode under the Background of Internet of Things Multimedia Communication
}

\author{
Qingxiang Liu ${ }^{1}$ and Zhongguo Yang $\mathbb{D}^{2}$ \\ ${ }^{1}$ College of Humanities and Social Sciences, Heilongjiang Bayi Agricultural University, Daqing 163319, China \\ ${ }^{2}$ College of Civil Engineering and Water Conservancy, Heilongjiang Bayi Agricultural University, Daqing 163319, China
}

Correspondence should be addressed to Zhongguo Yang; yzg111402@byau.edu.cn

Received 19 August 2021; Revised 18 September 2021; Accepted 4 October 2021; Published 13 October 2021

Academic Editor: Sang-Bing Tsai

Copyright () 2021 Qingxiang Liu and Zhongguo Yang. This is an open access article distributed under the Creative Commons Attribution License, which permits unrestricted use, distribution, and reproduction in any medium, provided the original work is properly cited.

\begin{abstract}
There are some problems in English smart classroom, such as slow response speed of related platforms and room for improvement of teaching effect. Therefore, it is necessary to construct English smart classroom and innovate teaching mode under the background of Internet of Things (IoT) multimedia communication. The teaching objectives are divided into classroom teaching objectives, curriculum objectives, and education and training objectives, so as to design the technical support for English smart classroom, that is, to build a smart classroom integrating cloud application platform (including students' learning cloud and teachers' teaching cloud), teaching platform, resource platform, learning space, and interactive classroom by using Internet of Things multimedia communication technology, and build an innovative teaching mode of English wisdom classroom. The fuzzy hierarchical evaluation model is used to design the fuzzy hierarchical evaluation algorithm. Through the fuzzy hierarchical evaluation algorithm, the teaching effect of smart classroom is evaluated, and the final evaluation result is obtained. The results show that the average platform login time of the proposed method is always below $0.3 \mathrm{~s}$, the average score of the summative evaluation is high, the evaluation time is always below $0.4 \mathrm{~s}$, the average communication delay is $0.54 \mathrm{~s}$, and the user satisfaction is always above 9.2. The practical application effect is better.
\end{abstract}

\section{Introduction}

At this stage, the emergence and application of multiple new technologies have brought great challenges and shock to traditional English classrooms, and traditional methods are unable to solve the defects and drawbacks in existing English classrooms [1]. Currently, there are many problems in English teaching, and thus the teaching effect is not so satisfactory, which motivates relevant personnel to explore the application of new methods and technologies, and smart classroom is born at this moment [2]. Smart classroom is mainly to improve and reconstruct English classes through new information technology in a bid to classes with higher quality and more efficiency [3]. Smart classrooms enable more intelligent and scientific teaching and learning so that students' personal advantages can be given full play, and students themselves can develop and grow more rapidly [4].

At present, certain progress has been made in the research into smart classroom both at home and abroad. For instance, based on the correct definition of English teaching practice in higher vocational colleges, Shi [5] analyzed its multidimensional characteristics in higher vocational smart classrooms in order to promote the construction and application of smart classrooms. Zhu and Chen [6] used the TPACK knowledge framework and deep learning theory to construct an evaluation index system for college English smart classroom teaching, in order to promote the transformation of college English classroom teaching from traditional teaching to smart classroom teaching. Yang and Yang [7] introduced modern high technology into 
conventional English education and teaching, allowing students and teachers to work together to play their subjective initiative. Besides, big data, cloud computing, mobile Internet, and other information technologies are used to realize intelligent, efficient, and smart classrooms in the whole process before, during, and after class. Zhao [8] scientifically allocates the input of information resources under the guidance of output derivation method (POA) theory, emphasizes learners' output ability, constructs a smart teaching model of College English, and realizes the effective connection and linkage between teaching and learning. Through the interpretation of related concepts in artificial intelligence, ecological linguistics and language education, literature [9] explores the concept of "smart education" and the construction path of college English ecological teaching mode, so as to build a smart English classroom. Through the analysis of the meaning of wisdom education and wisdom courses, a preliminary analysis of the wisdom teaching model was carried out, and $\mathrm{Xu}$ [10] constructed the structure of the wisdom teaching model based on related classic theories and emerging theories.

However, after studies, it is found that the existing research results have the problems of slow platform response rate and room for improvement in teaching effects. Therefore, a smart English classroom in the context of Internet of Things multimedia communication has been constructed, and English teaching models have been innovated. This research specifically includes the following contributions:

(1) Enhancing the intelligence level of the smart English classroom can meet the English learning needs of many people.

(2) Compared with traditional classrooms, smart classrooms have more significant advantages as a way of learning English.

(3) Through comparative analysis with other English smart classrooms, it is found that the designed English smart classroom has shortened the average login response time through the application of Internet of Things multimedia communication technology, and its online and offline teaching effects are better.

\section{Related Work}

The current research on English smart classrooms has also achieved some excellent research results. For example, literature [11] uses web2.0 tools in the construction of English smart classrooms, and it also uses the blended learning method to innovate the teaching model. There are also related scholars who have applied machine learning algorithms to construct English smart classrooms and designed an online English grading and test system. Hai [12] analyzes the Internet age, and smart oral English learning must keep up with the pace of the times, using various new information technologies to actively construct smart English classrooms. Therefore, the methods use network-based assistance and speech recognition technology to construct English smart classrooms to achieve auxiliary teaching of spoken English. Literature [13] proposes that in order to respond to the needs of educational information development and improve English teaching practice, it is very necessary to study the innovation path of English smart classroom in the process of educational and teaching innovation reform. Therefore, it is possible to analyze the feasibility of applying multimedia to the English smart classroom according to the actual situation of the students. On this basis, an English smart classroom was constructed through robust expression positioning and deep learning voice enhancement algorithms, and English multimedia teaching analysis was carried out. In China, diversified research studies have been conducted on the construction of smart English classrooms, mainly focusing on the application of information technology in the classroom and the wisdom of smart teachers and teaching.

This paper constructs English smart classrooms and innovative teaching models in the context of Internet of Things multimedia communication. The Internet of Things multimedia communication technology provides a technical foundation for the integration of English smart classrooms and information technology. Through the design of each part of the English smart classroom, three levels of teaching goals have been achieved, which can fully meet the actual needs of English education. The experimental results show that the average login time of the methods of this paper is always below $0.3 \mathrm{~s}$, the average score of summary evaluation is higher, the evaluation time is always maintained below $0.4 \mathrm{~s}$, and the actual application effect is better.

\section{Construction of Smart English Classroom under the Background of Internet of Things Multimedia Communication}

This article uses the Internet of Things multimedia communication technology to build a smart classroom based on the cloud application platform. The specific functions of the platform include resource sharing and co-construction, classroom feedback and interaction, discussion and communication, homework testing, cooperative learning, independent learning, teaching, and lesson preparation $[12,14]$. The platform mainly provides cloud services through cloud computing technology, that is, deploying smart classroom teaching applications on public cloud platforms through cloud computing technology, and realizes related communication functions through IoT multimedia communication technology. This deployment mode will not affect the development of teaching applications, but it can promote the optimization of computing and storage methods. It is shown in Figure 1.

This deployment model faces users and teaching application developers. Among them, teaching application developers use the form of local development to develop teaching applications through web server and Internet of Things multimedia communication and use Storage, Mysql, Channel, Memcache to store and manage teaching 


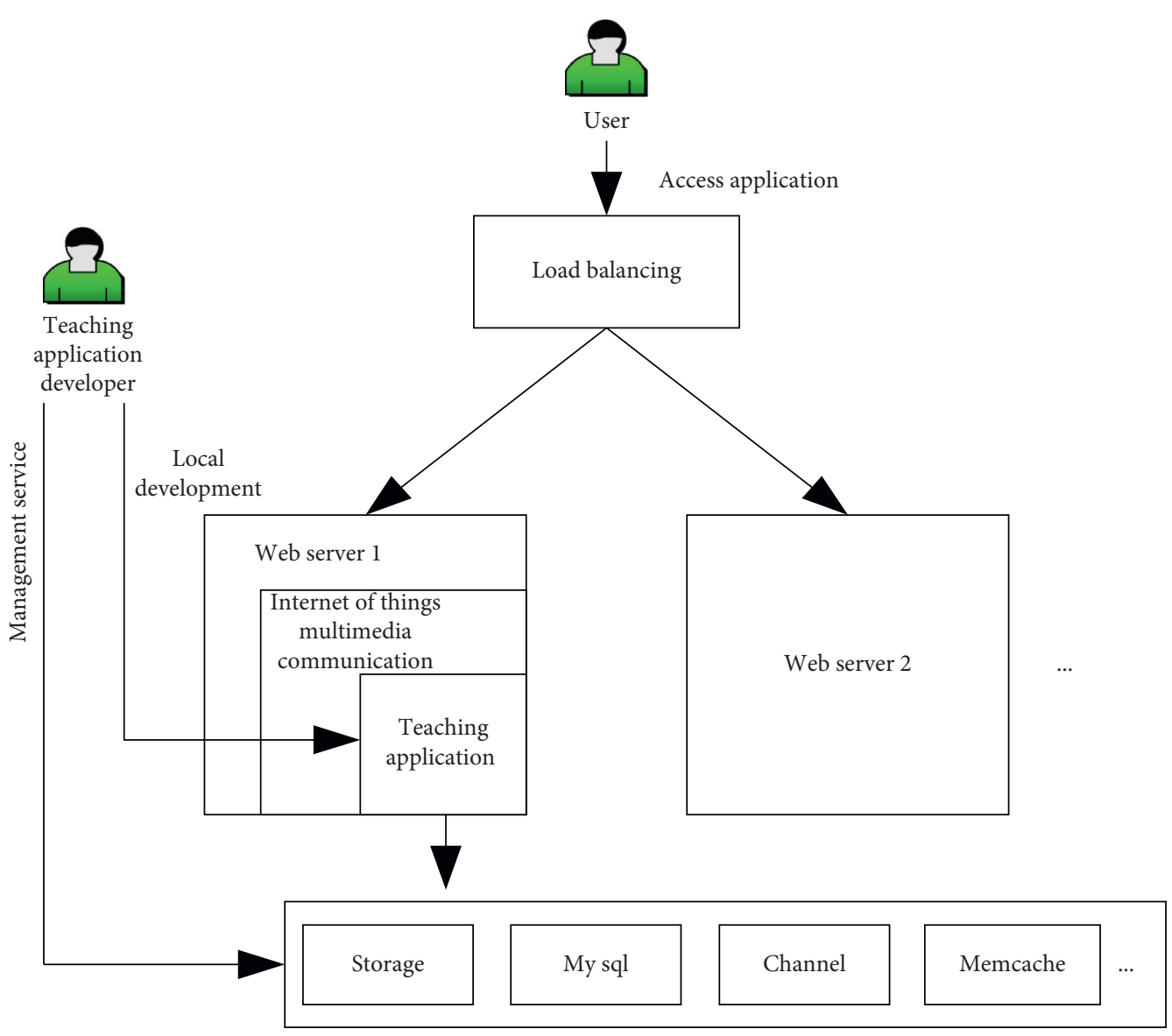

Figure 1: Deployment mode.

information. The user establishes communication with the accessed application through the web server. In order to avoid the problem of information congestion caused by too many users, it is necessary to carry out a load balancing design for the information transmission process to improve the efficiency of information transmission [15].

The built teaching platform can realize the functions of teaching support, management system and teaching resource library integration, and management of teaching organization. The platform mainly focuses on online teaching and the creation of high-quality resources. It is a resource platform integrating knowledge management and evaluation. The learning space in the smart classroom can provide relevant learners with services such as tutoring, online testing, group cooperation, interactive discussion, and online learning. The interactive classroom in the smart classroom can realize the seamless connection of afterschool review, class, and lesson preparation, shorten the distance between teachers and students and students and students, and enhance students' enthusiasm for learning $[13,16]$.

The platform is mainly composed of six modules: subject knowledge base module, theme learning module, simulation training module, personal knowledge management module, interactive communication module, and evaluation feedback module. The specific structure of the platform is shown in Figure 2.
3.1. Subject Knowledge Base Module. The main task of the subject knowledge base module is to classify, store, and manage English subject knowledge. The advantage of this module is that in addition to describing English learning knowledge points, it can also describe other knowledge points associated with it, so that users can build a better English subject knowledge network. It is shown in Figure 3.

3.2. Theme Learning Module. The main function of the theme learning module is to support the teaching activities of the English smart classroom in the context of the Internet of Things multimedia communication, including problem exploration, knowledge learning, simulation training, application practice, and other submodules.

3.3. Simulation Training Module. The main function of the simulation training module is to create a context-based oral expression environment for users, which can provide a video context segment, and then students can add words and voices to the character. Recording function shall be performed for subsequent correction analysis [17].

3.4. Personal Knowledge Management. Personal knowledge is the knowledge accumulation of users in the process of work and study and is the source of the improvement of 


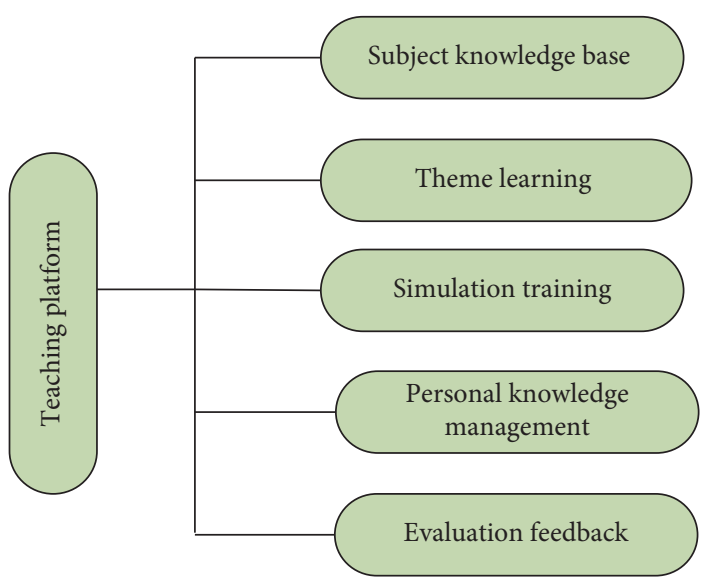

FIgURE 2: Teaching platform.

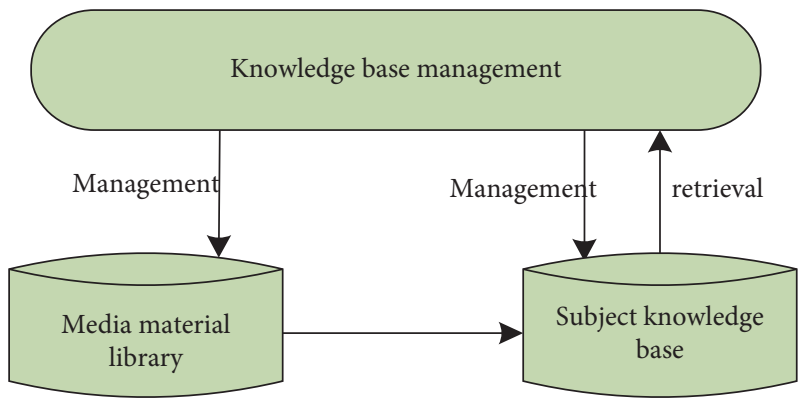

FIgURE 3: Subject knowledge base.

personal learning ability. The function of personal knowledge management is mainly to create a network environment that allows teachers and students to manage personal information and knowledge online.

3.5. Evaluation Feedback. Traditional teaching evaluation is mostly done by teachers correcting students' homework and examination papers or giving final results based on subjective impressions and observations. This evaluation method has certain drawbacks [18]. With the advancement of teaching informatization reform and the popularization of computers, the current teaching evaluation methods are becoming more diversified. Therefore, this paper uses the fuzzy hierarchical evaluation algorithm to evaluate the teaching effect of the smart classroom, which will be discussed in detail in the follow-up and will not be discussed here. It is shown in Figure 4.

\section{Innovative Teaching Mode}

This paper optimizes the design of the previous teaching mode and constructs an innovative teaching mode for English smart classroom. The specific content is as follows:

Step 1:

Teacher: intelligent teaching guide, i.e., to develop teaching plans after knowing students' situation.

Student: intelligent teaching guide, i.e., to propose doubts after independent learning.

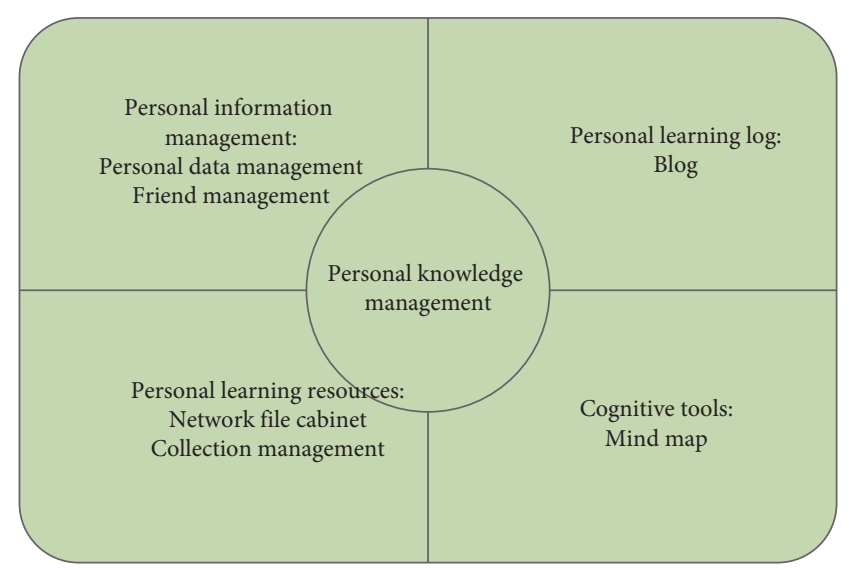

FIGURE 4: Specific functions of personal knowledge management module.

Step 2:

Teacher: exploring teaching, i.e., to conduct transfer training after summary and guidance.

Student: inquisitive learning, i.e., to deepen the learned knowledge after exploring questions.

Step 3:

Teacher: display and communicate, i.e., to display and exchange emotional strategies and methods.

Student: display and communicate, i.e., to display and exchange experience and knowledge ability.

Step 4:

Teacher: consolidate and extend knowledge, i.e., to reflect on and extract specific knowledge points.

Student: consolidate and extend knowledge, i.e., to consolidate and learn more relevant knowledge.

\section{Teaching Evaluation}

The teaching effect of the smart classroom is evaluated by the fuzzy hierarchical evaluation model. 
For the fuzzy hierarchical evaluation model, the setting of evaluation factors is as follows: as the teaching effect will be affected by many factors, $u_{i}$ is used to express factors from various aspects. When the number of influencing factors is $n$, $i=1,2, \ldots, n$. Suppose that these influencing factors are expressed in a collective manner, as shown in the following formula:

$$
U=\left\{u_{i} \mid i=1,2, \ldots, n\right\},
$$

where $U$ is the set of evaluation factors in teaching evaluation and $U$ is called the teaching evaluation factor in teaching evaluation.

For $U$, it reflects the importance of each factor and valuates the influence of teaching effect. The specific set of the value is as follows:

$$
A=\left\{a_{i} \mid i=1,2, \ldots, n\right\}
$$

where $a_{i}$ represents the influence degree value.

The influence degree value needs to meet the nonnegativity condition and the normalization condition, as shown in formulas (3) and (4).

$$
\begin{aligned}
& a_{1} \geq 0, \\
& \quad i=1,2, \ldots, n, \\
& a_{1}+a_{2}+\cdots+a_{n}=1 .
\end{aligned}
$$

Suppose $v_{i}$ is used to refer to the actual assessment result of teaching effect, and there are a total of $m$ kinds of assessment results. Then its set, that is, the evaluation result set, can be expressed by the following formula:

$$
V=\left\{v_{i} \mid i=1,2, . ., m\right\} .
$$

When the total number of evaluators is $s, v_{J}$ is used to refer to the corresponding evaluation results of $s_{I J}$ people. The formula of $S$ is as follows:

$$
S=\sum_{J=1}^{m} s_{I J} .
$$

For $v_{J}$, the affiliation degree of $U$ can be expressed in the following formula:

$$
\left\{\begin{array}{l}
r_{I J}=\frac{s_{U}}{S}, \\
i=1,2, \ldots, n, \\
j=1,2, \ldots, m,
\end{array}\right.
$$

where $r_{I J}$ means the affiliation degree of $U$ for $v_{J}$.

A matrix is used to express its degree of membership, as shown in the following formula:

$$
R=\left(\begin{array}{ccc}
r_{11} & \cdots & r_{1 m} \\
\vdots & \ddots & \vdots \\
r_{n 1} & & r_{n m}
\end{array}\right)
$$

When the result of a comprehensive fuzzy evaluation is recorded as $B$, the result is the fuzzy subset in set $V$. Multiply the corresponding items in each column of the formula (8) matrix by the set to obtain the following formula matrix $A$ :

$$
A^{\prime}=\left(\begin{array}{ccc}
a_{1} \cdot r_{11} & \cdots & a_{1} \cdot r_{1 m} \\
\vdots & \ddots & \vdots \\
a_{n} \cdot r_{n 1} & \cdots & a_{n} \cdot r_{n m}
\end{array}\right),
$$

where line $i$ in the matrix means the comprehensive assessment of $U$.

When the following formula is established:

$$
a_{i} \cdot r_{i j}=\max \left\{a_{i} \cdot r_{i j} \mid j=1,2, \ldots, m\right\},
$$

then the evaluation of $U$ is called $v_{j}$.

Add each column of the matrix, and then there is

$$
B=\left(\sum_{i=1}^{n} a_{i} r_{i j}, j=1,2, \ldots, m\right) .
$$

At this time, when the following formula holds:

$$
\sum_{i=1}^{n} a_{i} r_{i j}, j=\max (\mid j=1,2, \ldots, m),
$$

then the evaluation of $U$ is called $V_{j}$, i.e., the final result of the comprehensive fuzzy evaluation.

For more complex systems, a secondary comprehensive evaluation model needs to be constructed.

Define the following formula as a comprehensive fuzzy normalized judgment set:

$$
B^{*}=\left(b_{1}^{*}, b_{2}^{*}, \ldots, b_{n}^{*}\right) .
$$

The specific expression of $b_{j}^{*}$ is as follows:

$$
b_{j}^{*}=\frac{b_{j}}{\sum_{j=1}^{m} b_{j}}, \quad j=1,2, \ldots, m,
$$

where $b_{j}$ is the comprehensive fuzzy normalized evaluation results of item $j$ and $b_{j}^{*}$ is comprehensive fuzzy normalized evaluation index.

$b_{j}^{*}$ satisfies the following formula:

$$
\sum_{j=1}^{m} b_{j}^{*}=1
$$

The corresponding distribution status of the evaluated factor is indicated by $b_{j}^{*}$.

A fuzzy hierarchical evaluation model is used to design a fuzzy hierarchical evaluation algorithm. The flow of the algorithm is shown in Figure 5.

\section{Experimental Analysis and Results}

6.1. Experimental Environment and Dataset. In order to verify the effectiveness of the construction of English smart classroom and the innovative methods of teaching mode under the background of Internet of Things multimedia 


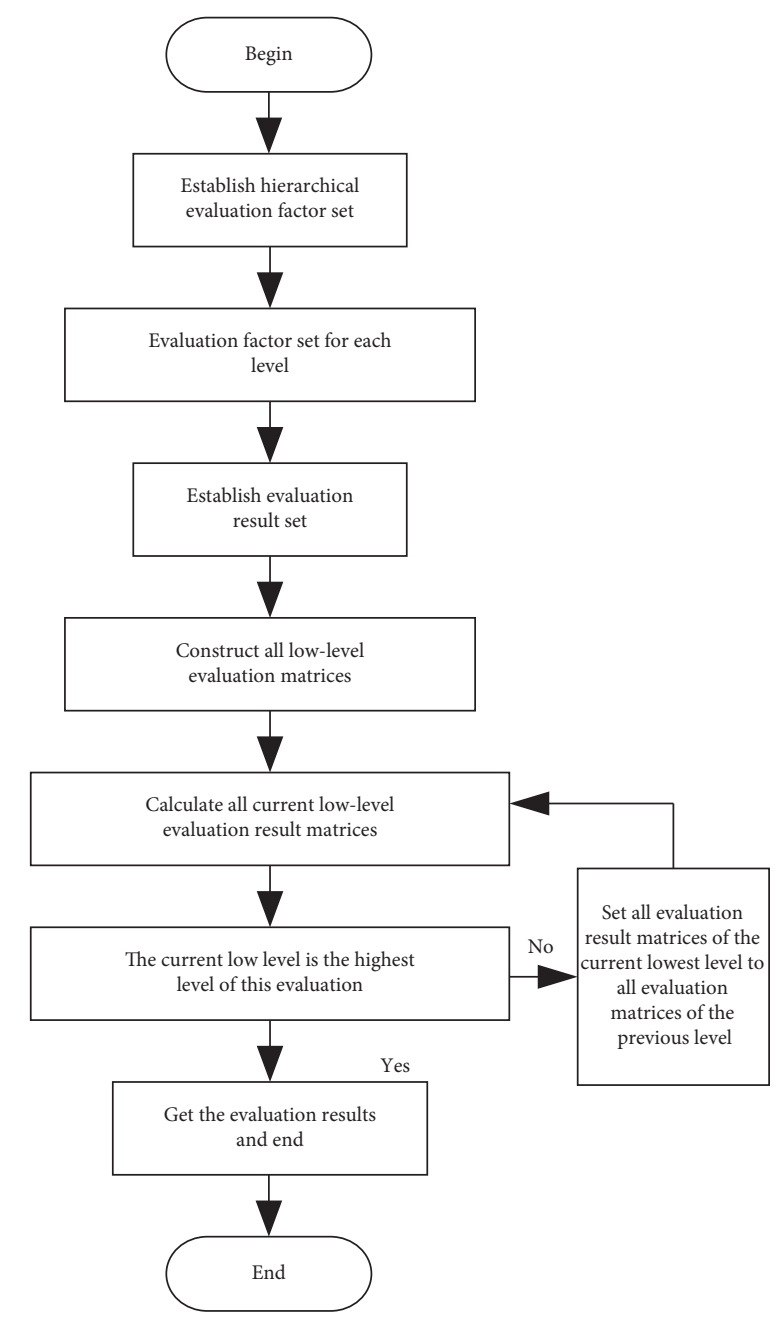

FIgURE 5: Flow of fuzzy hierarchical evaluation algorithm.

communication designed in this paper, experimental design is needed. It is shown in Table 1.

Collect experimental datasets during the application process of the English smart classroom under the background of the constructed Internet of Things multimedia communication. The collected teaching effect evaluation experimental dataset is a dataset made by collecting online and offline teaching effect data after the application of English smart classroom in a university. Divide the data into two datasets to evaluate the effect of smart English classroom teaching in the experiment.

Among them, dataset 1 mainly contains data such as students' classroom performance and learning experience, while dataset 2 mainly contains data such as teachers' classroom performance and teaching effect evaluations made by students. The dataset comes from the questionnaire survey of many colleges and universities. It mainly obtains the relevant evaluation results of teachers and students on the curriculum in the form of network questionnaire. During the experiment, the online and offline English smart classroom application data were collected in an all-round way, and the collected data were classified and put into the corresponding experimental datasets.
TABLE 1: Experimental environment.

\begin{tabular}{lc}
\hline Name & Parameter \\
\hline Operating system & Windows 7 \\
CPU & Intel Core i5-7300HQ \\
Memory & $32 \mathrm{G}$ \\
Hard disk & $500 \mathrm{~GB}$ \\
Running memory & $8 \mathrm{G}$ \\
Dominant frequency & $2.1 \mathrm{GHz}$ \\
Simulation software & Matlab R2014a \\
\hline
\end{tabular}

The online data include students' learning effect data, participation data, and learning attitude data. Offline data include students' classroom interaction data, interest and attitude data, learning status data, learning harvest data, teachers' teaching design data, teaching implementation data, and teaching evaluation data.

6.2. Experimental Indicators. The methods in this paper, the methods in literature [11], the methods in literature [12], and the methods in literature [13] are used as experimental comparison methods, and the average login time, evaluation effect, and evaluation time of different methods are compared as evaluation indicators.

(1) Average login time: the various platforms designed in the smart classroom, including cloud application platforms, teaching platforms, resource platforms, learning spaces, and interactive classrooms, are tested for their response speed. When the number of logins on each platform is 100 , the average login response time is tested.

(2) Evaluation effect: this paper uses the two datasets collected in the experiment to evaluate the online teaching effect of the application of English smart classroom. Among them, the online teaching effect is mainly evaluated for the online teaching part, which is mainly evaluated from three stages, including three stages before class, during class, and after class. This part of the application is mainly the online learning data of the English smart class, which is mainly divided into two parts for evaluation. The first part is a summary evaluation, and the second part is a process evaluation.

The hierarchical evaluation factor set constructed in the experiment is the learning effect evaluation factor set $u_{1}$, students' participation evaluation factor set $u_{2}$, and learning attitude evaluation factor set $u_{3}$. The hierarchical evaluation factor set is as follows:

$$
U=\left\{u_{1}, u_{2}, u_{3}\right\}
$$

According to the three kinds of evaluation factor sets, the corresponding influence degree set is constructed to construct the evaluation result set.

(3) Evaluation time: evaluation time refers to the time it takes to get the evaluation result. The specific calculation formula is as follows: 


$$
T=\sum_{i=1}^{n} t_{i},
$$

where $t_{i}$ means the time for the $i$ assessment, and the unit is $s$.

(4) Communication delay: as the Internet of Things multimedia communication technology is an important basis for building an English smart classroom, it is required that the technology must have a low communication delay. Therefore, the communication delays of different methods are compared, and the calculation formula is as follows:

$$
t=t_{s}-t_{e},
$$

where $t_{s}$ and $t_{e}$ represent the sending time and receiving time of the data packet, respectively.

(5) User satisfaction: the teachers and students participating in the questionnaire are divided into 10 groups on average, so that the teachers and students can score the satisfaction of English smart classroom, with a maximum score of 10 points and a minimum score of 0 points. The results of each group are taken as the average value.

\subsection{Results and Discussion}

6.3.1. Comparison of Average Login Time. The average login time of this method is compared with that of literature [11], literature [12], and literature [13] in this paper. It is shown in Figure 6.

According to Figure 6, the average login time of the methods in this paper has always been kept below $0.3 \mathrm{~s}$, which is much lower than that of the experimental comparison methods. Therefore, it proves that the response rate of each platform of the intelligent English classroom in the context of the Internet of Things multimedia communication is higher than that of the comparative English intelligent classroom due to the application of the multimedia communication technology of the Internet of Things. This proves that through the application of the Internet of Things multimedia communication technology, the design of an English smart classroom has successfully shortened the average login response time.

6.3.2. Comparison and Evaluation of Online Teaching Effect. The learning effect of online data in the experimental dataset is evaluated by fuzzy hierarchical evaluation algorithm, and the evaluation results are summarized from two parts. In the online teaching effect evaluation experiment, the methods in literature [11], the methods in literature [12], and the English smart classroom proposed in literature [13] are used as comparisons to obtain the comparison experiment results of the two indicators of online teaching effect evaluation. It is shown in Table 2.

Analyzing the data in Table 2 shows that comparing the above calculation results, it is found that the average score of

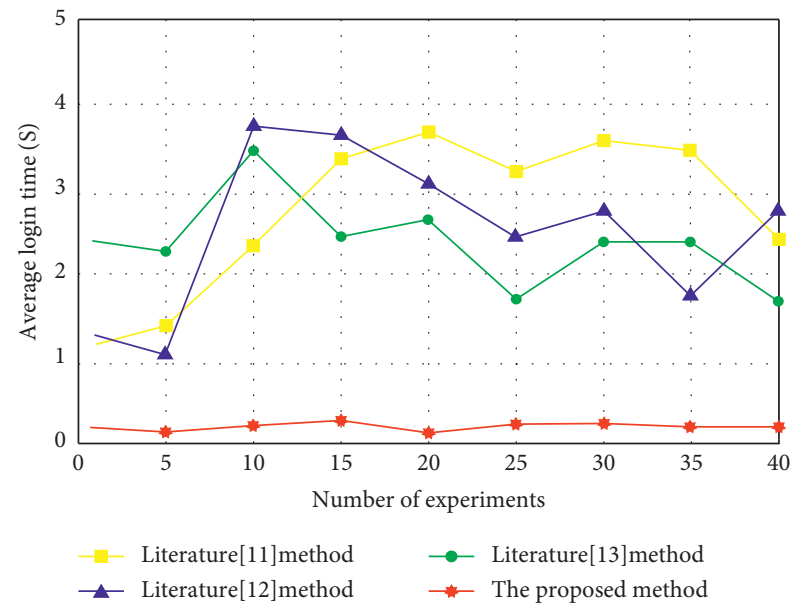

Figure 6: Test results of average login response time.

the summary evaluation of the English smart classroom under the background of the designed Internet of Things multimedia communication is higher. This proves that the English smart classroom under the background of the Internet of Things multimedia communication has obtained a higher teaching effect score, and its online teaching effect is better.

6.3.3. Comparison of Evaluation Time. This study compares the average login time of methods in this paper, methods in literature [11], methods in literature [12], and methods literature [13]. It is shown in Figure 7.

Compared with the methods in literature [11], methods in literature [12], and methods in literature [13], the evaluation time of methods in this article has always been kept below $0.4 \mathrm{~s}$. This shows that the evaluation efficiency of this method is higher, it can realize the rapid evaluation of the quality of smart classroom teaching, and the practical application effect is good.

6.3.4. Comparison of Communication Delay. Based on the above experiments, the communication delays of different methods are compared, and the results are shown in Table 3.

According to Table 3, it can be seen that the average communication delay of the proposed method is $0.54 \mathrm{~s}$, the average communication delay of the method in literature [11] is $1.53 \mathrm{~s}$, the average communication delay of the method in literature [12] is $1.89 \mathrm{~s}$, and the average communication delay of the method in literature [13] is $1.6 \mathrm{~s}$. Compared with other literature methods, the communication delay of this method is the shortest because this method uses the Internet of Things multimedia communication technology to build an English smart classroom, and the communication delay is low.

6.3.5. Comparison of User Satisfaction. Finally, the user satisfaction of English smart classroom constructed by this method and the methods in literature [11], literature [12], 
TABLE 2: Online teaching effect evaluation scale (scores 1-10).

\begin{tabular}{|c|c|c|c|}
\hline Evaluation dimension & Evaluation indicator & Evaluation content & Evaluation score \\
\hline \multirow{6}{*}{ Process evaluation } & \multirow[t]{2}{*}{ Learning effect } & Platform usage & $\begin{array}{l}\text { The proposed method: } 8.6 \text { points } \\
\text { Method in literature [11]: } 7.2 \text { points } \\
\text { Method in literature [12]: } 6.8 \text { points } \\
\text { Method in literature [13]: } 6.3 \text { points } \\
\text { The proposed method: } 9.2 \text { points }\end{array}$ \\
\hline & & Preview duration & $\begin{array}{l}\text { Method in literature [11]: } 6.9 \text { points } \\
\text { Method in literature [12]: } 5.2 \text { points } \\
\text { Method in literature [13]: } 6.7 \text { points } \\
\text { The proposed method: } 8.8 \text { points }\end{array}$ \\
\hline & \multirow{3}{*}{ Student participation } & \multirow[t]{2}{*}{ Exchange and discussion } & $\begin{array}{l}\text { Method in literature [11]: 6.6points } \\
\text { Method in literature [12]: } 6.9 \text { points }\end{array}$ \\
\hline & & & $\begin{array}{l}\text { Method in literature [13]: } 6.1 \text { points } \\
\text { The proposed method: } 9.0 \text { points }\end{array}$ \\
\hline & & Teacher-student interaction & $\begin{array}{l}\text { Method in literature [11]: } 5.9 \text { points } \\
\text { Method in literature [12]: } 8.2 \text { points } \\
\text { Method in literature [13]: } 5.9 \text { points } \\
\text { The proposed method: } 8.5 \text { points }\end{array}$ \\
\hline & Learning attitude & Completion of operation & $\begin{array}{l}\text { Method in literature [11]: 6.3points } \\
\text { Method in literature [12]: } 4.8 \text { points } \\
\text { Method in literature [13]: } 6.2 \text { points }\end{array}$ \\
\hline \multirow{4}{*}{ Summative evaluation } & \multirow{4}{*}{ Stage learning effect } & \multirow[t]{2}{*}{ Group evaluation } & $\begin{array}{l}\text { The proposed method: } 8.6 \text { points } \\
\text { Method in literature [11]: } 4.9 \text { points } \\
\text { Method in literature [12]: } 5.7 \text { points }\end{array}$ \\
\hline & & & $\begin{array}{l}\text { Method in literature [13]: } 6.3 \text { points } \\
\text { The proposed method: } 9.1 \text { points }\end{array}$ \\
\hline & & \multirow{2}{*}{ Total course score } & Method in literature [11]: 6.8points \\
\hline & & & $\begin{array}{l}\text { Method in literature [12]: } 7.5 \text { points } \\
\text { Method in literature [13]: } 6.7 \text { points }\end{array}$ \\
\hline
\end{tabular}

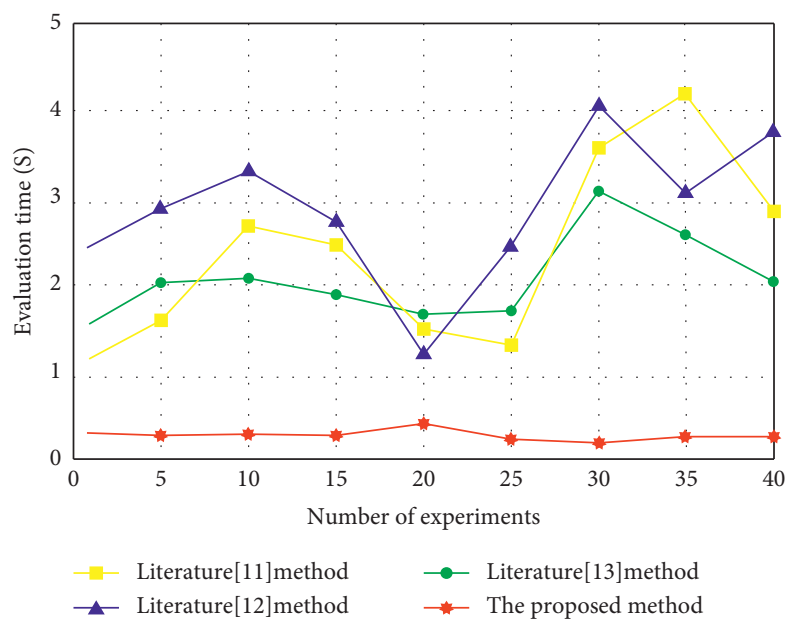

Figure 7: Comparison of evaluation time.

TABLe 3: Comparison of communication delay.

\begin{tabular}{lcccc}
\hline Number of experiments & The proposed method & Method in literature [11] & Method in literature [12] & Method in literature [13] \\
\hline 5 & 0.56 & 1.58 & 2.11 & 1.41 \\
10 & 0.47 & 1.44 & 0.95 & 0.66 \\
15 & 0.38 & 1.95 & 1.84 & 1.47 \\
20 & 0.49 & 1.38 & 2.33 & 1.57 \\
25 & 0.63 & 1.28 & 2.45 & 1.63 \\
30 & 0.64 & 1.24 & 2.67 & 1.47 \\
35 & 0.54 & 1.66 & 2.14 & 1.85 \\
40 & 0.57 & 1.71 & 1.89 & 1.6 \\
Average value & 0.54 & 1.53 & & \\
\hline
\end{tabular}


TABle 4: Comparison of user satisfaction.

\begin{tabular}{lcccc}
\hline Number of experiments & The proposed method & Method in literature [11] & Method in literature [12] & Method in literature [13] \\
\hline Group 1 & 9.2 & 8.1 & 6.3 & 6.1 \\
Group 2 & 9.5 & 8.3 & 6.8 & 7.1 \\
Group 3 & 9.7 & 8.1 & 7.2 & 7.3 \\
Group 4 & 9.4 & 7.4 & 6.9 & 6.4 \\
Group 5 & 9.3 & 7.9 & 6.4 & 6.5 \\
Group 6 & 9.5 & 7.2 & 6.8 & 6.1 \\
Group 7 & 9.4 & 7.3 & 6.5 & 6.9 \\
Group 8 & 9.3 & 7.5 & 6.2 & 7.2 \\
Group 9 & 9.6 & 7.1 & 6.7 & 7.5 \\
Group 10 & 9.4 & 7.7 & & \\
\hline
\end{tabular}

and literature [13] is compared. The comparison results are shown in Table 4.

According to Table 4, it can be seen that the user satisfaction of the method in literature [11] varies from 7.1 to 8.3 , the user satisfaction of the method in literature [12] varies from 6.2 to 7.2 , and the user satisfaction of the method in literature [13] varies from 6.1 to 8.8. However, the user satisfaction of the method in this paper remains above 9.2, and the user satisfaction with the English smart classroom is higher.

\section{Conclusions}

In order to solve the problems of long platform login time, poor evaluation effect, and long evaluation time existing in the current methods of constructing English smart classrooms, this paper constructs English smart classrooms and innovative teaching models in the context of Internet of Things multimedia communication. The Internet of Things multimedia communication technology provides a technical foundation for the integration of English smart classrooms and information technology. Through the design of each part of the English smart classroom, three levels of teaching goals have been achieved, which can fully meet the actual needs of English education. The experimental results show that the average login time of the methods of this paper is always below $0.3 \mathrm{~s}$, the average score of summary evaluation is higher, the evaluation time is always maintained below $0.4 \mathrm{~s}$, and the actual application effect is better. However, it was also found that there is still a lot of room for improvement in the designed English smart classroom because it became popular during the experiment and did not apply it for a long time. In the future, it is necessary to improve the details of the platform in long-term practice and application, so as to further enhance the effect of English teaching.

\section{Data Availability}

The data used to support the findings of this study are included within the article.

\section{Conflicts of Interest}

The authors declare that there are no conflicts of interest.

\section{Acknowledgments}

This study was supported by the Philosophy and Social Science Planning Foundation of Daqing Heilongiiang Province of China, under Grant No. DSGB2016087, and Higher Education Reform Foundation of Heilongjiang Province of China, under Grant No. SJGY20200507.

\section{References}

[1] M. Fautley and A. Daubney, "The whole class ensemble tuition programme in English schools-a brief introduction," British Journal of Music Education, vol. 36, no. 3, pp. 223-228, 2019.

[2] Q. Meng and L. Tang, "An artificial intelligence based construction and application of English multimodal online reading mode," Journal of Intelligent and Fuzzy Systems, vol. 40, no. 1, pp. 1-10, 2020.

[3] P. Cao, "Research on the construction and effect of mixed teaching model of ESP course based on flipped classroom," Foreign Language Circles, vol. 201, no. 6, pp. 88-95, 2020.

[4] T. T. T. Nguyen, "Building teacher capacity in Vietnamese English language teaching: research, policy and practice," ELT Journal, vol. 74, no. 2, pp. 232-234, 2020.

[5] X. Shi, "Multidimensional analysis of "informatization" factors in Higher Vocational English smart classroom in the "Internet+" era," Journal of Hunan Institute of Industry and Technology, vol. 18, no. 1, pp. 76-78, 2018.

[6] Y. Zhu and L. Chen, "Construction of evaluation index system for College English smart classroom teaching," Foreign Language Audio Visual Teaching, vol. 194, no. 4, pp. 96-102, 2020.

[7] B. Yang and S. Yang, "Constructing middle school English smart classroom based on three principles," China Journal of Education, vol. 317, no. 9, Article ID 116, 2019.

[8] B. Zhao, "Construction of College English intelligent teaching model guided by POA theory in the mobile new media environment," Educational Theory and Practice, vol. 39, no. 3, pp. 53-54, 2019.

[9] C. Hong, "Research on the construction of College English ecological teaching model in the era of artificial intelligence," Foreign Language Audio-Visual Teaching, vol. 3, no. 6, pp. 29-34, 2018.

[10] J. Xu, "Research on Intelligent curriculum construction in Higher Vocational Education from the perspective of intelligent education," Vocational Education Forum, vol. 6, no. 12, pp. 52-56, 2019.

[11] V. V. Malinee and T. Senthamarai, "The use OF web 2.0 tools IN English for specific purpose: a blended learning approach IN English language teaching," Journal of Shanghai Jiaotong University, vol. 16, no. 8, pp. 703-716, 2020. 
[12] Y. Hai, "Computer-aided teaching mode of oral English intelligent learning based on speech recognition and network assistance," Journal of Intelligent and Fuzzy Systems, vol. 39, no. 4, pp. 5749-5760, 2020.

[13] K. Hao, "Multimedia English teaching analysis based on deep learning speech enhancement algorithm and robust expression positioning," Journal of Intelligent and Fuzzy Systems, vol. 39, no. 3, pp. 1-13, 2020.

[14] M. J. Maluleke, "Using code-switching as an empowerment strategy in teaching mathematics to learners with limited proficiency in English in South African schools," South African Journal of Education, vol. 39, no. 3, pp. 1-9, 2019.

[15] L. Hu, Q. Zeng, X. Wu, and Z. Lv, "Simulation of English classroom effectiveness based on human-computer interaction and facial identification," Journal of Intelligent and Fuzzy Systems, vol. 40, no. 3, pp. 1-12, 2020.

[16] Y. Zhang, "Interactive intelligent teaching and automatic composition scoring system based on linear regression machine learning algorithm," Journal of Intelligent and Fuzzy Systems, vol. 40, no. 2, pp. 2069-2081, 2021.

[17] R. Duan, Y. Wang, and H. Qin, "Artificial intelligence speech recognition model for correcting spoken English teaching," Journal of Intelligent and Fuzzy Systems, vol. 40, no. 1, pp. 1-12, 2020.

[18] Q. Lin, Y. Zhu, S. Zhang, P. Shi, Q. Guo, and Z. Niu, "Lexical based automated teaching evaluation via students' short reviews," Computer Applications in Engineering Education, vol. 27, no. 1, pp. 194-205, 2019. 